\title{
Springback Simulation of U-channel Forming Process based on Finite Element Analysis
}

\author{
Altaye Girum Temechache ${ }^{1}$, Prof. Men Changfeng ${ }^{2}$, Lie Duan ${ }^{3}$, Han Chui Hong ${ }^{4}$ \\ School of Mechanical Engineering, Tianjin University of Technology and Education, Tianjin, 300222, P.R.China
}

\begin{abstract}
The phenomenon of springback is an inevitable common defect in sheet stamping process. In order to improve the forming quality of stamping parts and shorten the test time of the actual production of die, accurate prediction and effective control of the springback of stamping parts are necessary. U-shaped parts are one of the representative parts in sheet metal forming. This feature appears on many auto body cover panels such as side members and beams. The springback in the process of U-shape/channel stamping forming is difficult to resolve, especially the rebound of steel plate. How to accurately predict and control the springback effectively, there are many people in the study. This paper used a standard S-Rail as a benchmark [1] and finite element simulation analysis software DYNAFORM to simulate the forming and springback of parts. Finite element meshing and forming parameters settings are performed in the forming model of parts. Then the defect is analyzed in the forming process. To solve the fracture defect by optimizing the blank-holder force, it is used DYNAFORM software to do springback simulation of forming parts. Through the analysis of the springback of part, the springback compensation is made by offsetting the die surface. After compensation, the second drawing and springback simulation is also done. Compare and contrast the displacement value of before and after compensation. It is found that the simulation results of springback compensation and the springback of before compensation are minimized by fifty percent, thus it is validated that the method of offsetting die surface is effective in the compensation of springback.
\end{abstract}

Keywords: Finite Element Analysis, Numerical simulation, Sheet Metal Forming, springback compensation, DYNAFORM

\section{Introduction}

The u-shaped part is a common element in sheet metal forming. It appears in many auto-body cover panels like side members and beams. The central concern in forming Ushaped parts is the effect of springback on the geometry. Springback can be defined as an elastically -driven change of shape of a deformed product which takes place during removal of external loads. It is a complex physical phenomenon which is mainly governed by the stress state obtained at the end of a deformation. Depending on the product geometry and deformation regime, there are several types of springback in sheet metal forming: bending, membrane, twisting and combined bending and membrane [2]. Pure bending springback can be observed after bending a material in plane strain. Membrane springback takes place during the unloading of a material from in-plane tension or compression. The twisting type of springback can be observed while forming components with large deference's in sectional dimensions, such as for example shallow panels [3]. This type of springback is the result of uneven elastic recovery in different directions. The combined bending and membrane springback is the type which is most commonly observed in industrial practice. The product geometry is usually so complex that the material is bent out-of-plane and simultaneously stretched or compressed in-plane.
In the applications of sheet metal there are many cases while deforming the sheet metal; the component fractures at certain point. The causes of the failure are parameters related to forming process. Hence these parameters must be taken into consideration. In recent years stamping simulation applications have grown enormously, as the benefits of troubleshooting and optimizing processes through the computer rather than through extensive shop trials have been realized. The rapid development of software technology, together with faster and lower cost computer hardware, has enabled many metal forming operations to be modeled costeffectively. LS-DYNA has been widely used for sheet metal forming simulation since1993. ETA developed a specialized sheet metal forming software package including LS-DYNA, pre-processor and postprocessor. In this paper, firstly Springback simulation and compensation of U-Channel forming process will be done and analyzing the results of the springback before and after compensation.

\section{FE modeling and Simulation setup}

Sheet metal stamping process of CAE analysis process is shown in figure 1. Using ETA/Dynaform5.9 [4] software for sheet metal forming CAE analysis, generally can be divided into four steps. 
International Journal of Science and Research (IJSR)

ISSN (Online): 2319-7064

Index Copernicus Value (2013): 6.14 | Impact Factor (2014): 5.611

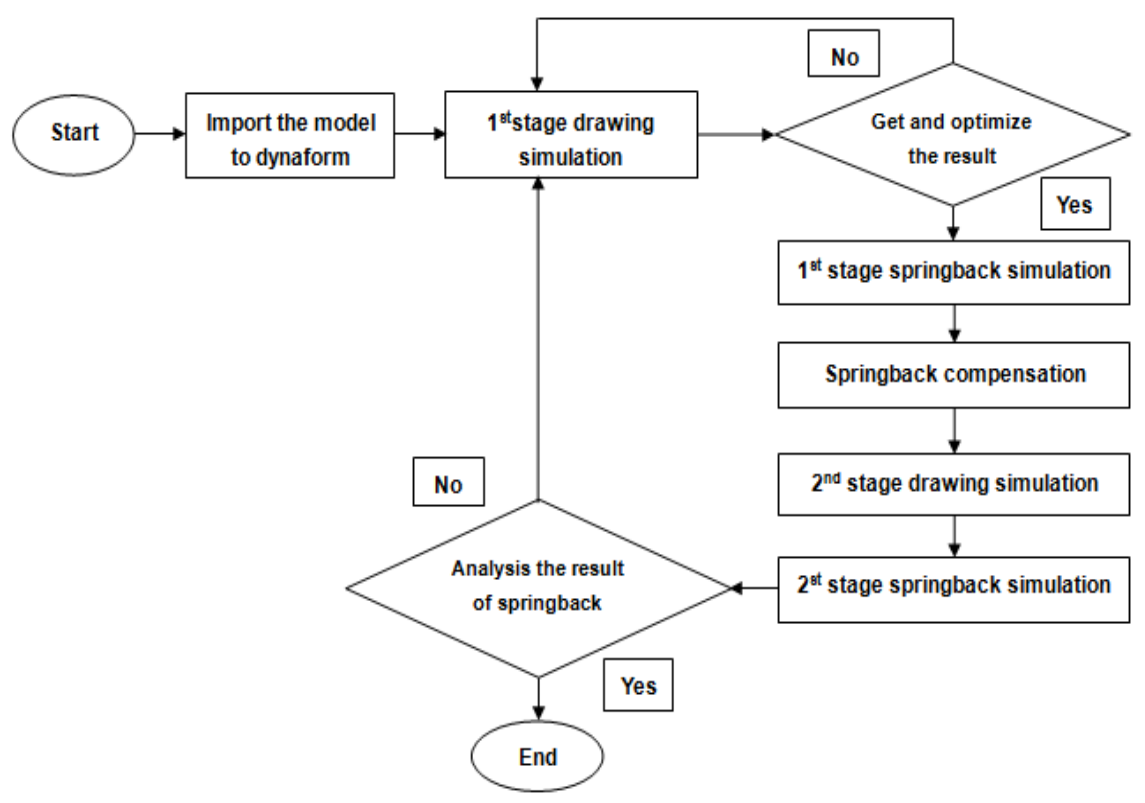

Figure 1: Finite Element simulation process flow

1) Modeling of the required tools, Import the blank and the tools into dynaform. (File formats can be IGES, VAD, CATIA, and UG).

2) Pre-processing: In pre-processing step the following parameters are defined:

- The geometry of the problem.

- $\quad$ The finite element type to be used.

- The material properties of the elements.

- The element connectivity's (meshing).

- The physical constraints (boundary conditions).

- $\quad$ The loadings (force, pressure...).

3) Submit the job and calculate the solution.

4) Post-processing: Sorting, printing and plotting of the selected results of the FE solution are achieved. By using an appropriate FE software, the elemental stresses-strains, the deformed shape of the model and the animation of the process can be evaluated at this step and finally the engineering judgment of the solution is done whether the results are reasonable or not.

Drawing simulation: based on the Auto setup's steps are, defining basic parameters; in the first draw auto setup we use the sheet forming simulation type, single action process for the drawing stage and $1 \mathrm{~mm}$ thickness of sheet metal. Then Blank definition and material selection where the material that is used in this study is DQSK37, then tool definition and Positioning where the tools are defined according to their function, positioning and their activeness. Tool position is related to the working direction of every tool, then the Process definition where the blank-holder force is 40,45t and 50t as calculated from the punch dimensions and the other parameter as default, lastly the job submitter using LS-DYNA solver to calculate the results.

\section{Drawing Simulation Results}

After getting the result using the job submitter, the post processor can read and process all the available data in the D3PLOT file. The D3PLOT file also contains all requested result data (stress, strain, time history data, deformation, etc.). Eta/DYNAFORM will automatically create a new database called "*.d3plot" into which we will read in the D3PLOT file directly. And the prediction and elimination of process failures such as cracking, wrinkling and excessive thinning is one among the important objectives of conducting process simulations.

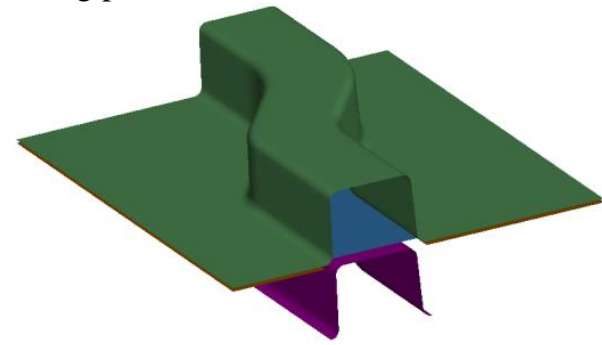

Figure 2.Complete process model.
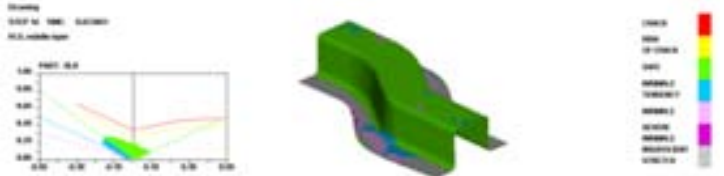

a) 40 t Blank-holder force FLD
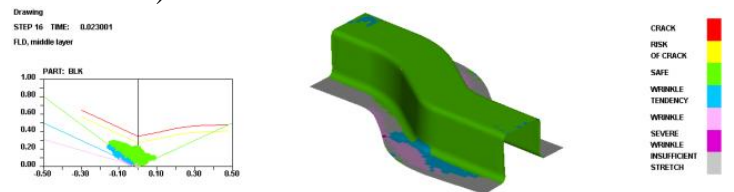

b) 45 t Blank-holder force FLD
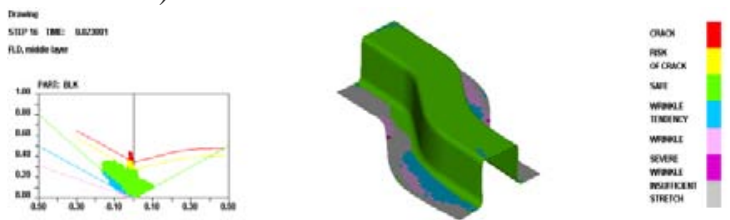

c) 50 t Blank-holder force FLD

Figure 3: The forming limit diagram (FLD) of different blank-holder force.

The forming limit diagram (FLD) of figure 3A and B shows failure of insufficient stretch and wrinkle tendency. In the case of figure $3 \mathrm{C}$ in addition to the above defects shows a problem of crack. In FLD the major strain represented vertically and the minor strain horizontally. All states in which the deformation becomes unstable can be connected 


\section{International Journal of Science and Research (IJSR) ISSN (Online): 2319-7064 \\ Index Copernicus Value (2013): 6.14 | Impact Factor (2014): 5.611}

graphically and then form a forming limit curve (FLC). The FLC gives an impression of the formability of sheet material calculated strains, as we can see there are crack and wrinkle at some points which should be eliminated.

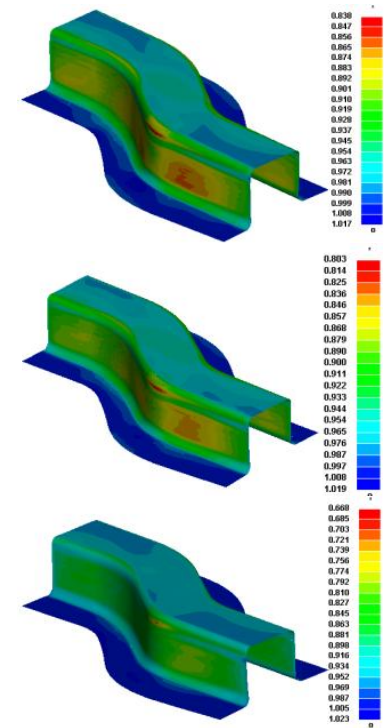

Figure 4: Thickness distribution of the design in 40t, 45t and 50t blank-holder force respectively.

Figure 4 shows the thickness value distribution, as we can see at the same points on the FLD diagram where the crack and the wrinkle happened the thickness is serious. In the case of $40 \mathrm{t}$ the minimum thickness is $0.838 \mathrm{~mm}$ and in $50 \mathrm{t}$ the value will be $0.668 \mathrm{~mm}$. According to the result of thickness and the above FLD shows 40t blank-holder force other parameters constant preferable to the next process. So all this phenomena's must be avoided before the springback simulation stage.

Springback simulation: Import DYNAIN (*dynain*) file from the drawing job submit after optimizing files and save the database. In this article about the U-channel plate springback simulation calculation method for choosing dynain method, the blank-holder force after the forming/drawing results of 40t. After the springback simulation Settings, the program automatically uses full integration element formulation then set and defines boundary condition (constraint points), process and control parameters. Lastly submit the jobs using LS-DYNA solver to calculate the results.

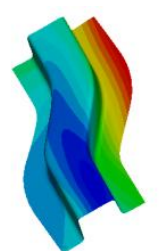

A

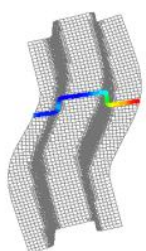

C
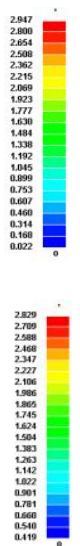

Figure 5: Springback displacement distribution (A), B, C\&D position of springback displacement distribution

\section{Compensation}

Can be seen from the figure $5 \mathrm{~A}$ the springback displacement value is larger; it needs the springback compensation on the part using offset surface method. The offset surface method is based on the analysis of stamping springback simulation results or the actual product measurement values, to find springback laws and location of parts. According to the position of springback laws, to modify the surface shape and complete compensation [5].

Full file the necessary parameters springback compensation will be done and submit the job. After springback compensation calculation, attainment a new tool and check the tool if it is under cut or not. Finally go to the second drawing and springback simulation process.

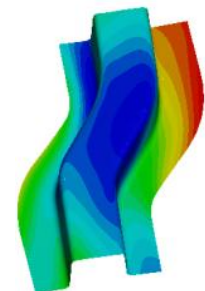

A

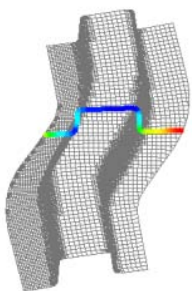

C

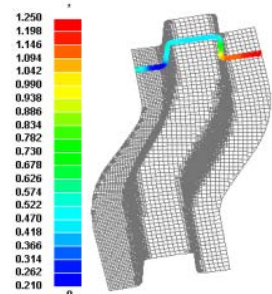

B

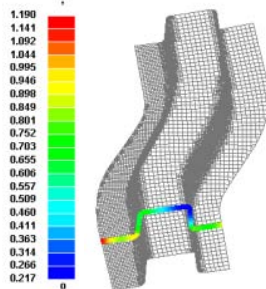

$\mathrm{D}$
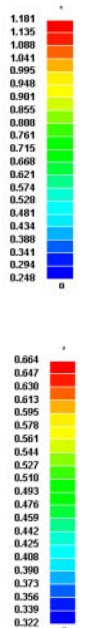

Figure 6: Whole springback displacement distributions (A), and B, C \& D position of springback displacement distribution.

\section{Results Optimization}

Figure 6A to be shows the whole springback displacement distribution of after compensation. The maximum springback displacement is $1.25 \mathrm{~mm}$. The next table shows the amount of springback before and after compensate of the part in selected position.

Table 1: Amount of springback before and after compensate.

\begin{tabular}{|c|c|c|c|}
\hline \multicolumn{2}{|c|}{ Forming parts } & \multicolumn{2}{|c|}{ The amount of springback (mm) } \\
\cline { 3 - 4 } \multicolumn{2}{c|}{} & Before compensation & After compensation \\
\hline \multirow{2}{*}{ Overall } & Min. & 0.022 & 0.210 \\
\cline { 2 - 4 } & Max. & 2.947 & 1.250 \\
\hline Position B & Min. & 1.196 & 0.528 \\
\cline { 2 - 4 } & Max. & 2.890 & 1.181 \\
\hline position C & Min. & 1.142 & 0.509 \\
\cline { 2 - 4 } & Max. & 2.829 & 1.190 \\
\hline Position D & Min. & 0.526 & 0.425 \\
\cline { 2 - 4 } & Max. & 1.759 & 0.664 \\
\hline
\end{tabular}

\section{Conclusion}

Computer simulation can be used to obtain appropriate springback results, optimize other processing parameters, reduce costs and shorten design cycle. 


\section{International Journal of Science and Research (IJSR) \\ ISSN (Online): 2319-7064}

Index Copernicus Value (2013): 6.14 | Impact Factor (2014): 5.611

In the present study the effect of the process parameters on the formation of fracture and wrinkle were investigated. The forming, springback and springback compensation simulations will be done. In the process of drawing parts, through the optimization of blank holder force, from 50t to $40 \mathrm{t}$, solved the first forming cracks defects and select the appropriate blank holder force. Compeer and contrast the amount of springback before and after compensation. The result of our simulation successfully reduced above fifty percent the springback.

\section{References}

[1] ETA/DYNAFORM User's Manual, version 5.9, Engineering technology associates, Inc.

[2] C.Wang. An industrial outlook for springback predictability, measurement reliability and compensation technology. In D.-Y. Yang, S.I. Oh, H. Huh, and Y.H. Kim, editors, Proceedings of the 5th International Conference and Workshop on Numerical Simulation of 3D Sheet Forming Processes, NUMISHEET 2002, pages 597-604, Jeju Island, Korea, 2002.

[3] E.H. Atzema, H. Kappert, A.W.A. Konter, S.E. Meijers, and T. Meinders. Sensitivity analysis component 2: Scaled down car roof. Netherlands Institute for Metals Research, 2005.

[4] Hong-ying gong. Stamping sheet metal forming CAE practical tutorial $[\mathrm{M}]$. Beijing: chemical industry press, 2010:17-19.

[5] Jiang Kuihua. Stamping process and die design [M]. Beijing: mechanical industry press, 1998:109-110. 